\title{
Spinal Muscular Atrophy Type II: Anesthetic Challenges and Perioperative Management
}

\author{
Suvendu Panda ${ }^{1}$ S. K. Rojalin Baby ${ }^{1}$ Guriqbal Singh ${ }^{2}$ \\ ${ }^{1}$ Department of Anesthesiology, Indraprastha Apollo Hospital, \\ New Delhi, India \\ ${ }^{2}$ Department of Cardiac Anesthesiology, U.N. Mehta Institute of \\ Cardiology \& Research Centre, Ahmedabad, Gujarat, India \\ Address for correspondence Suvendu Panda, MD, 103, Atulyam 1, \\ Ahmedabad Cantonment Road, Meghaninagar, Ahmedabad, Gujarat \\ 380016, India (e-mail: suvendu00panda@gmail.com). \\ J Card Crit Care 2021;5:249-251.
}

\begin{abstract}
Keywords

- spinal muscular atrophy

- neuromuscular disease

- scoliosis

Spinal muscular atrophy (SMA) is a group of genetic diseases that cause weakness and wasting in voluntary muscles of infants and children and more rarely in adults. It is caused by inadequate production of a protein called survival motor neuron (SMN) protein coded by SMN1 gene on chromosome 5. Anesthetic challenges in patients of SMA include their sensitivity toward induction agents such as thiopental, opioids, muscle relaxants, and their incomplete reversal with anticholinesterases. They also have weakness of respiratory muscles and inadequate laryngeal reflexes, which make them prone to aspiration. Although spinal and epidural anesthesia have been described in adults with SMA, but general anesthesia in these patients is very challenging. In this case, successful perioperative management of such a patient scheduled for correction of dislocated hip has been described.
\end{abstract}

\section{Introduction}

Spinal muscular atrophy (SMA) is an autosomal recessive neuromuscular disease, affecting 7.5 to 8 cases per 100,000 live births. It is inherited lethal disease in children characterized by progressive symmetrical muscle weakness affecting proximal muscles more than distal muscles; however, sensory functions remain intact. The genetic defect in SMA is homozygous deletion of exon 7 in survival motor neuron gene (SMN1) on chromosome 5 (5q11.2-13.3). Anesthetic challenges in these patients include hypersensitivity to nondepolarizing muscle relaxants, succinylcholine-induced hyperkalemia, presence of weak laryngeal reflexes predisposing them to gastric aspiration, weak inspiratory respiratory muscles with inability to cough making them prone to recurrent pneumonia and postoperative pulmonary dysfunc- tion, and risk of deep venous thrombosis because of lack of muscle activity and risk of hypoglycemia.

\section{Case Report}

An 8-year-old boy having class I obesity with body mass index of $33 \mathrm{~kg} / \mathrm{m}^{2}$ presented with right hip dislocation and was posted for open reduction of dislocated hip with pelvic osteotomy and medial hamstring release operation. History showed that patient was diagnosed as a case of SMA at the age of 14 months with muscle biopsy and had undergone an unsuccessful stem cell transplant 3 years ago. On examination, patient was well oriented to time, place, and person with normal higher neurological functions, and there was no sensory deficit. Weakness in lower limbs was more than
DOI https://doi.org/ $10.1055 / s-0042-1742401$. ISSN 2457-0206.
(C) 2022. Official Publication of The Simulation Society (TSS), accredited by International Society of Cardiovascular Ultrasound (ISCU). All rights reserved.

This is an open access article published by Thieme under the terms of the Creative Commons Attribution-NonDerivative-NonCommercial-License, permitting copying and reproduction so long as the original work is given appropriate credit. Contents may not be used for commercial purposes, or adapted, remixed, transformed or built upon. (https://creativecommons.org/ licenses/by-nc-nd/4.0/)

Thieme Medical and Scientific Publishers Pvt. Ltd., A-12, 2nd Floor, Sector 2, Noida-201301 UP, India 
upper limbs. Upper limb power was grade 2/5 and lower limb was $1 / 5$. Patient was having thoracolumbar scoliosis with Cobb angle of 30 degrees. Examination of airway and other systems was unremarkable. Preoperative investigations including complete blood count, serum urea, creatinine, electrolytes, bilirubin, and prothrombin time were normal. Patient was adequately fasted according to standard American Society of Anesthesiologists guidelines and since patient was high risk for gastric aspiration, a bedside gastric ultrasound examination was performed in supine and right lateral decubitus position to check for residual gastric volume in preoperative area and was not found to be at risk of aspiration. Patient was shifted to operating room accompanied by his mother. Standard monitors were applied to patient and was induced under inhalational agent using sevoflurane and slowly increasing its inspired concentration to $8 \%$ in $100 \%$ oxygen. Once patient lost consciousness, peripheral line was secured with 18-gauge intravenous cannula and injection fentanyl $2 \mu \mathrm{g} / \mathrm{kg}$ and injection propofol $2 \mathrm{mg} / \mathrm{kg}$ were administered. Airway was secured with oral Portex cuffed endotracheal tube no. 6.5 without giving muscle relaxant. Radial artery cannulation was done with 20 -gauge intracath for invasive arterial monitoring and to facilitate frequent sampling. Epidural space was located under ultrasound guidance in $\mathrm{L}_{3}-\mathrm{L}_{4}$ space with 18-gauge Tuohy needle and loss of resistance was felt at $6 \mathrm{~cm}$ in left lateral position. Spinal anesthesia was given with 27-gauge Whitacre needle in same space with $2 \mathrm{~mL}$ of $0.5 \%$ hyperbaric bupivacaine and epidural catheter was threaded and fixed at $10 \mathrm{~cm}$. On aspiration of catheter, there was no cerebrospinal fluid or blood. Epidural infusion of $0.2 \%$ ropivacaine at the rate of $5 \mathrm{~mL} / \mathrm{h}$ was started 2 hours after induction and was continued throughout the surgery. Surgery was started and maintenance of anesthesia was done with 1 monitored anesthesia care sevoflurane and $60 \%$ nitrous oxide in $40 \%$ oxygen and patient was spontaneously ventilated with pressure support. There was significant blood loss (450-500 mL) and was replaced with one unit of packed red blood cells. Intraoperative fluid management was done by giving injection ringer lactate at the rate of $10 \mathrm{~mL} / \mathrm{kg} /$ $\mathrm{h}$ and injection $5 \%$ dextrose in $0.45 \%$ saline was infused at the rate of $2 \mathrm{~m} / \mathrm{kg} / \mathrm{h}$ to prevent hypoglycemia and 2 hourly blood sugar was checked. Surgery lasted for 5 hours. After the completion of surgery, inhalational agents were switched off and once patient gained consciousness, extubation was done and patient was shifted to pediatric intensive care unit for observation for 24 hours, which was uneventful. Patient was shifted to surgical ward with epidural in situ, which was taken out on fourth postoperative day and patient was discharged on fifth postoperative day.

\section{Discussion}

SMA constitutes a group of autosomal recessive disorders characterized by progressive weakness of lower motor neurons and is associated with degeneration of anterior horn cells of spinal cord and sometimes loss of neurons in brain stem motor nuclei. Based on the age of onset of clinical features, it is classified into four types:
SMA type I: Patients present before 6 months of age. They have severe progressive muscle weakness, which affects proximal muscles more than distal. Type 1 SMA progresses rapidly leading to frequent respiratory infections and death by the age of 2 years.

SMA type II: It is most common form of SMA with most children presenting between the age of 6 and 18 months, and there is significant motor delay and having postural tremors affecting fingers. Children cannot get a sitting position on their own. Life span of patients vary from 2 years to third decade of life.

SMA type III: It is a mild form of SMA that appears after the age of 18 months and is slowly progressive proximal muscle weakness.

SMA type IV: It typically appears in mid-30s and course of the disease is benign and patients have normal life expectancy. ${ }^{1}$

Very little information is available in literature regarding anesthetic management of such cases. Adult cases are successfully managed with spinal, epidural, and general anesthesia with total intravenous anesthesia. ${ }^{1-4}$ Some studies have successfully used rocuronium in these patients, reversing the effect with sugammadex. ${ }^{5}$ Our patient was a young child and was posted for prolonged and difficult surgery and hence needed to be asleep. In this case, narcotics were avoided by using epidural analgesia with local anesthetic. The postoperative pain control was satisfactory in this patient.

\section{Conclusion}

According to the experience gained from this case, we suggest that general anesthesia with combined spinal epidural anesthesia without the use of neuromuscular blocking agents is a good anesthetic choice for patients with SMA.

\section{Authors' Contribution}

S.P. and S.K.R.B. conceptualized and designed the study; manuscript preparation was done by them; and both the authors were the guarantor. Definition of intellectual content and clinical studies were done by S.P. Literature search was done by all the authors and they edited the manuscript. Manuscript review was done by S.K.R.B. and G.S.

\section{Conflict of Interest}

None declared.

\section{References}

1 Harris SJ, Moaz K. Caesarean section conducted under subarachnoid block in two sisters with spinal muscular atrophy. Int J Obstet Anesth 2002;11(02):125-127 
2 Habib AS, Helsley SE, Millar S, Deballi P III, Muir HA. Anesthesia for cesarean section in a patient with spinal muscular atrophy. J Clin Anesth 2004;16(03):217-219

3 Veen A, Molenbuur B, Richardson FJ. Epidural anaesthesia in a child with possible spinal muscular atrophy. Paediatr Anaesth 2002;12(06):556-558
4 Watts JC. Total intravenous anaesthesia without muscle relaxant for eye surgery in a patient with Kugelberg-Welander syndrome. Anaesthesia 2003;58(01):96-96

5 Islander G. Anesthesia and spinal muscle atrophy. Paediatr Anaesth 2013;23(09):804-816 